\title{
Is Workplace Bullying in the Eye of the Beholder
}

\section{Siobhán Healy-Cullen}

\begin{abstract}
This article presents a study of employees' opinions on the definitional Issues with workplace bullying and examines employees' viewpoints on how personal subjectivity should be weighed when reviewing workplace bullying complaints
\end{abstract}

\section{Keywords}

Workplace, bullying, victim

\section{Introduction}

This study uses a single site case study utilising participants who are employees within the education sector in Ireland. A mixed method approach was taken by combining both quantitative and qualitative analyses.

Primarily, the study's findings show that there are significant variances in individuals' viewpoints and definitions as to what constitutes bullying in the workplace.

Additionally, it was found that the majority of employees believe that there is a questionable line between 'banter' and bullying and that subjective individual perceptions should be taken into account when reviewing bullying complaints. This is relevant for mediators working in these cases and for those, such as human resources professionals, who pass judgment on workplace bullying complaints.

\section{Rationale}

At present, there are many different viewpoints surrounding how to define and classify bullying in the workplace, yet the opinions of workers are often overlooked. To disregard the employee voice may be considered negligent, given the documented undesirable effects workplace bullying can have on the target, other employees and the organisation itself (Vartia, 2001; Di Rosa et al, 2009).

This study aims to achieve a better understanding as to what employees subjectively classify workplace bullying to be and where they draw the line between workplace 'banter' and workplace bullying. The issue of objective and subjective bullying is one of the many contentious issues that surrounds workplace bullying and a substantial gap in the literature currently exists on this topic (Beswick, Gore \& Palferman, 2006). This present study aims to contribute to this neglected area of research. The findings of this study are particularly relevant for those in the profession of workplace mediation, who are 
often called upon to work with human resources professionals, work and organisational psychologists and other conflict specialists when reviewing bullying complaints (Jenkins, 2011). Mediation services, as opposed to formal investigations or hearings, are highlighted here as mediation often provides a platform for the subjective experiences of the victim to be accounted for, as opposed to investigations which are evidence-based.

\section{Conceptual context}

The literature base for this study is built upon Brodsky's work in 1976 surrounding subjective versus objective bullying experiences and Niedl's (1995) subsequent affirmation which states that the "definitional core of bullying at work rests on the subjective perception made by the victim that these repeated acts are hostile, humiliating and intimidating and that they are directed at himself/herself'.

More recently, Parzefall and Salin (2010) have outlined their beliefs, stating that bullying is a "subjective experience that resides in the eye of the beholder".

Lazarus and Folkman (1984) have analysed subjective appraisal, which explains how one employee may deem a behaviour to be worthy of a bullying complaint while another employee may be completely oblivious to the offence this behaviour may cause another individual (Tersptra and Baker, 1991). The primary focus of this present study is to gain a better understanding of the subjective perception surrounding workplace bullying.

\section{Background}

Bullying in the workplace has become a worldwide concern for organisations since Swiss psychologist Heinz Leymann's pioneering work in the 1990s (Saunders, Huynh, \& Goodman-Delahunty, 2007) and has been described as a "more crippling and devastating problem for employees than all other kinds of work-related stress put together" (Einarsen, Hoel, Zapf \& Cooper, 2003). Over the years, much research has focused on the different behavioural manifestations of workplace bullying (Ayoko, Callan, \& Hartel, 2003; O'Driscoll et al., 2011) and the negative effects associated with this workplace bullying on the victim and the workplace itself, such as: a reduction in employee performance, organisational commitment and employee well-being and an increase in employee stress (Vartia, 2001; Ayoko, Callan, \& Hartel, 2003). Much research has also focused on establishing which individuals may be susceptible to falling victim to bullying versus adopting a bullying role (Zapf \& Einarsen, 2011; Ayoko, Callan, \& Hartel, 2003).

Recently, there has been a vast array of research surrounding the area of workplace bullying and the consequent interest in this topic has led to many organisations worldwide introducing anti-bullying practices either in collaboration with or under the scrutiny of Trade Unions (Einarsen, Hoel, Zapf and Cooper, 2003). 


\section{Definition}

Despite these procedural developments, researchers and authorities concerned with workplace bullying have yet to agree upon a globally accepted definition as to what constitutes bullying in the workplace.

Norwegian researcher Ståle Einarsen and his colleagues (2003) have coined the following widely cited definition:

"Bullying at work means harassing, offending, socially excluding someone or negatively affecting someone's work tasks. In order for the label bullying (or mobbing) to be applied to a particular activity, interaction or process it has to occur repeatedly and regularly (e.g. weekly) and over a period of time (e.g. about six months). Bullying is an escalating process in the course of which the person confronted ends up in an inferior position and becomes the target of systematic negative social acts. A conflict cannot be called bullying if the incident is an isolated event or if two parties of approximately equal 'strength' are in conflict."

Rayner and Keashly (2004) have also contributed to this literature, outlining five components which they have identified as usually being included when researchers attempt to define what they consider workplace bullying to be:

1. The targeted employee is exposed to negative behaviour towards them

2. These behaviours are on-going and persistent

3. Either psychological or physical injury or harm is induced on thevictim

4. There is considered to be a power imbalance by the target, be this real or not, and targets feel an inability to defend themselves

5. Targets refer to themselves as having been bullied

However, the debate still rages as to which components are most pertinent. Of these five components, the negative harm experienced by the target and the conduct of carrying out negative behaviour in the workplace are the elements which have received the most reinforcement in the literature. The other elements of persistence, power and the self-identification of being bullied are being regarded as less essential and defining elements of workplace bullying (Rayner \& Keashly, 2004).

Einarsan et al. (2003) outline the issue of the personal subjectivity of bullying and the varying perceptions of bullying in the workplace. The limit and threshold whereby negative behaviours become bullying is ambiguous in the literature and differs depending on the individual. Thus, having defining elements outlining what constitutes bullying is crucial in assessing targets' bullying accusations and their subjective opinions that they have been bullied (Saunders, Huynh, \& Goodman-Delahunty, 2007). Bentley (2012) also suggests that, even given the wide pool of definitions surrounding workplace bullying to guide researchers, it is the individual's perception and subjective view of the negative behaviour being directed towards them that will matter, and the actual conduct being portrayed is somewhat irrelevant if 
the target perceives the action as bullying. There is also ambiguity and definitional issues around the concept of 'banter'. In linguistic studies, Leech's 'Banter Principle' states that one must say something which is (a) obviously untrue, and (b) obviously impolite to the hearer (Leech, 1983). A more standardised definition is that of the Oxford English Dictionary (2017) which defines banter as "the playful and friendly exchange of teasing remarks" or "to exchange remarks in a good-humoured teasing way". It is apparent from these vague definitions why there would be discrepancies in the understanding of the word 'banter'. These definitions give rise to questions such as what constitutes being impolite or what is considered teasing versus bullying? Further clarification is required as to when offending behaviours cross the line from harmless banter to inappropriate behaviour in the workplace.

\section{Personal resilience}

Personal resilience, which has been defined as "the ability of an individual to adjust to adversity, maintain equilibrium, retain some sense of control over their environment, and continue to move on in a positive manner", also needs to be considered when discussing workplace bullying (Jackson, Firtko \& Edenborough, 2007). Stemming from Rutter's research, which described the notion of resilience as a continuum with vulnerability and resilience at opposite ends of the spectrum (Rutter, 1985; Kulig, 2000), it is accepted that some people are more capable of dealing with adversity, such as bullying, than others. Furthermore, Rutter's (1985) work aided the creation of the Connor-Davidson Resilience scale (CDRISC) (Connor and Davidson, 2003). This scale comprises 25 items created to measure resilience levels of individuals and each response is recorded on a 5 point Likert scale. Utilising this tool could offer employers an insight into which employees are more vulnerable and which are more resilient, potentially allowing for greater support networks to be offered to those who are less resilient in the workplace (Connor and Davidson, 2003).

Greater resilience can also be attributed to particular personality traits, such as self-confidence, self-discipline, emotional stability or those who are extroverts and thus less likely to perceive negative behaviours as bullying or to feel personally victimised (Tugade and Frederickson, 2004).

\section{Subjective individual perceptions}

An interesting area of research is that of the different situational perceptions of the victim and the perpetrator. Einarsen, Raknes and Matthiesen (1994) discuss how a target may be an employee who is viewed by colleagues as fussy, sensitive or difficult and so treatment of that particular individual may be perceived by third parties as a fair course of treatment in some instances. Yet, the victim may still perceive themselves as being a victim of bullying.

Hoel, Rayner, \& Cooper (1999) discuss further how third party subjective perceptions are not always equivalent to the victim's subjective perceptions. Therefore, for the significance of the behaviour to be recognised, in some instances, the subjective component of the victim's perception needs to be acknowledged as well as other observable measures. Baumeister et al (1990) gives the example of a 
perpetrator not being aware that an action was perceived as negative or offensive by the victim if no anger or upset is shown, and so the action may be repeated.

Salin (2001) also notes how the subjective viewpoint of the target will always be crucial regardless of the behaviour carried out as the target will still reactin the way she or he deems appropriate given the target's perception of the behaviour, and the target's response may then negatively affect the organisation.

\section{Self-identification as a victim}

There is also an on-going discussion surrounding the broad discrepancy between selfidentification and self-labelling of bullying victims and the objective identification of bullying victims (Ireland \& Ireland, 2000). In a study conducted by Salin (2001) it was objectively established that approximately a quarter of the participants were considered to be victims of bullying, but just under 9\% of participants personally perceived themselves as being victims of bullying. The lack of a clear definition as to what workplace bullying is was noted as a possible reason for this discrepancy. This inconsistency in self-labelling can consequently lead to a lack of coherence and, as outlined by Keashly and colleagues (1994): "extensive individual variability in the perceived severity of bullying interaction . . . influencing whether the conduct is deemed sufficiently severe to warrant the 'bullied' label".

Mikkelsen and Einarsen (2001) suggest that this self-labelling may be indicative of the form used to identify bullying victims and whether this is operational or subjective. The former approach involves the employee identifying themselves as a bullying victim based on their own self-labelling. In operatonal self-labelling, when prompted by their employer they will perceive that they have experienced a negative behaviour within a certain timeframe outlined for them. The latter (subjective) approach involves the selfidentification and report of being a bullying victim based only on a set definition outlined for employees. Using an operational approach has been found to increase the prevalence of self-identification reports as bullying victims (Mikkelsen and Einarsen, 2001).

\section{Industry-specific factors}

With regard to bullying in the education sector, the majority of research tends to focus on pupil peer-to-peer bullying. However, the National Association of School Masters and Union of Women Teachers (NASUWT, 1996) conducted a survey which surveyed 3,500 teachers in England and Northern Ireland in 1995 and 1996 to assess bullying among the adult school workforce. Notably, the survey found that of those who responded, $72 \%$ reported as having been either victims of or witnesses to bullying behaviour. This led to a significant proportion of $20 \%$ of these reported victims leaving their positions as a way of evading the bullying (NASUWT, 1996). These statistics suggest a wide prevalence of bullying amongst teachers and indicate the need for further recent research in this particular occupation. 


\section{Legislation}

The National Survey of the Task Force on Workplace Bullying (2001) in Ireland acknowledges clearly that bullying is a subjective experience: "What one person may consider to be bullying behaviour may not accord with the view of another," and that individual perceptions should be a very real consideration in bullying situations. Despite recommendations made in the report to introduce firmer codes of practice, no specific legislation has been created regarding workplace bullying in Ireland. While the Task Force did debate whether to introduce new laws to outlaw bullying, it was decided instead that it would be better to use the existing laws, with the proviso that it may be necessary later to reconsider on the need for new legislation. A definition was also established by the Task Force (2001) which is considerate of the concepts of dignity and respect:

"Workplace bullying is repeated inappropriate behaviour, direct or indirect, whether verbal, physical or otherwise, conducted by one or more persons against another or others, at the place of work and/or in the course of employment, which could reasonably be regarded as undermining the individual's right to dignity at work. An isolated incident of the behaviour described in this definition may be an affront to dignity at work but as a one-off incident is not considered to be bullying."

Ultimately, the HSA has been granted responsibility for issues arising related to workplace bullying. The HSA website also concedes that "bullying can be very difficult as it is hinged on perceptions and subjective assessments of what is appropriate and what is not". The HSA and acts such as the Industrial Relations Acts, 1946-1990 have some bearing on controlling workplace bullying. However, Ireland is still institutionally lagging behind many of the Scandinavian countries and Australia, where antibullying laws have been established (Quine, 1999; Jenkins, 2011).

It should also be noted that, according to the Employment Equality Act 1998- 2015, sexual harassment and the harassment of an employee in the workplace are against the law. The updated Code of Practice on Sexual Harassment and Harassment (2012) outlines how 'unwanted conduct' is subjectively defined by the victim: "It is up to each employee to decide what behaviour is unwelcome, irrespective of the attitude of others to the matter." The Act also states that "bullying that is not linked to one of the nine discriminatory grounds is not covered by the Employment Equality Act", and therefore is not against the law. 
These above points of discussion may be represented as a visual schematic:

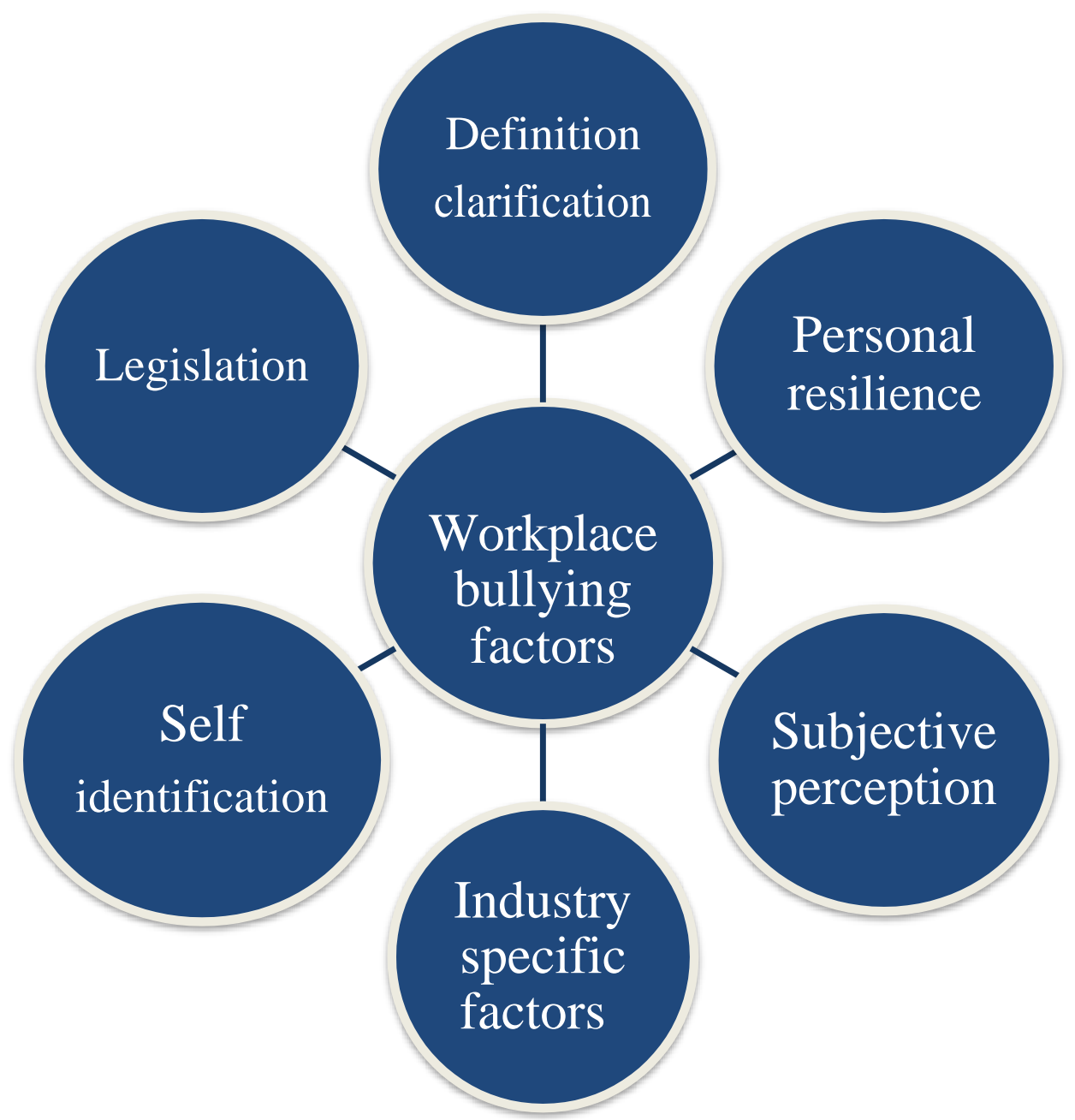

Figure 1. Factors to be considered when reviewing workplace bullying complaints

\section{Research design}

A mixed method approach was taken for this study to allow for an overall comprehensive perspective by combining both quantitative (survey data) and qualitative (focus group) analysis.

\section{Findings - quantitative}

Participants were all teachers $(N=17)$ in employment at a Secondary School in Ireland with an age range of 18-65 years and a female to male gender ratio of 15:2. 


\section{Scale Statistics}

\begin{tabular}{|l|l|l|l|}
\hline Mean & Variance & $\begin{array}{l}\text { Standard } \\
\text { deviation }\end{array}$ & $\begin{array}{l}\text { Number of } \\
\text { items }\end{array}$ \\
\hline-.5294 & 101.015 & 10.05061 & 12 \\
\hline
\end{tabular}

The large gap between the variance and the mean is an indication of the significant discrepancy between participants' opinions regarding the 'bullying' scenarios given in the survey, revealing the personal subjectivity involved when concerning workplace bullying.

\section{Example: Question 15}

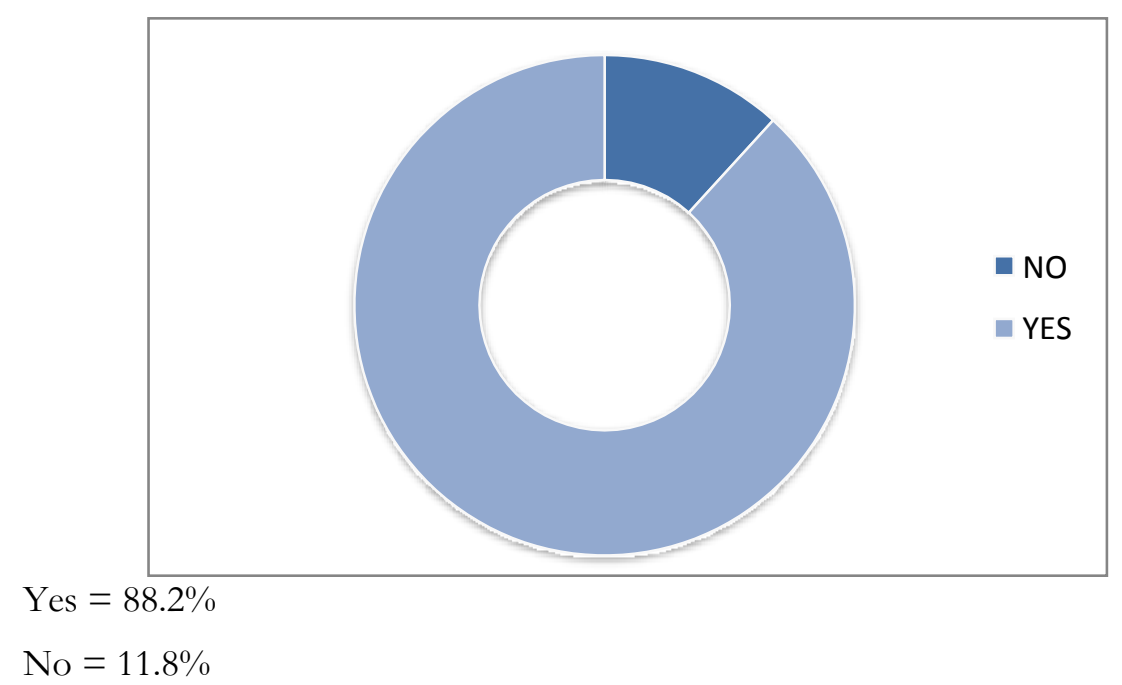

Figure 2. 'Do you think that some people may view a situation as 'a bit of banter'/ 'harmless teasing' while others may view the same situation as bullying?' (Question 15 - one comment: "If it causes upset to someone then it is not banter")

\section{Findings - qualitative}

\section{Identification of victims}

Participants felt that labelling and identifying victims of workplace bullying may be a difficult task due to a number of factors. The issue of denial and desire to avoid stigma was raised:

"Maybe I might not want to be honest with myself and say I am being bullied

.. you don't want to be perceived as unable to cope or stigmatised as someone who is being bullied" (Participant 2) 
Another alternate finding emerged with regard to labelling and identification that there may be people who label themselves as bullying victims too lightly:

'There are people with victim mentalities and you feel like saying: 'would you just get on with it.' They have a sense of victimisation" (Participant 1)

Participants also noted how self-awareness and awareness of others may be a factor in victim identification:

"It depends on how aware the person is of their own self and can realise that they are an overly sensitive person" (Participant 4)

\section{Resilience}

With regard to an individual's resilience levels and how this may influence bullying complaints, participants felt that the concept itself of individuals having different levels of resilience and sensitivity should be taken into consideration and that training and awareness of this concept would be beneficial:

"Resilience training and personal development may be more pressing than resilience assessment." (Participant2)

\section{Subjective perceptions}

Participants recognised that subjective perceptions are an issue when it comes to assessing workplace bullying complaints and essentially it is how the individual victim feels they are affected that is important to note.

"Bullying is horrific . . but bullying can be in the eye of the beholder, even if it is harsh to say." (Participant 1)

'There is definitely a line between banter and bullying. You need to respect everyone's rights, and if my dignity is affected, whether yours would be or not in the same situation, is immaterial. It is about dignity and how you are left feeling." (Participant 3)

\section{Industry specific factors}

Participants commented that the particular industry they worked in, the Irish secondary school education system, may be an environment where workplace bullying is more common than others due to a number of different factors.

"Education is different - in our job you can be bullied in the classroom, by a parent, by management, by a colleague. Another environment is different. The nature of our job, it can come from all angles, and it is high pressure." (Participant 2)

\section{Banter versus bullying scenario opinions}

Participants had a scenario read to them by the researcher and were asked to discuss. The overall consensus was that the scenario would not be considered to be a 'bit of banter' and that this incident would have crossed the line in this regard. However, the only male participant disagreed with the four 
other female participants and stated;

"T wouldn't think that is bad now. It is just a bit of a laugh. That would be a bit of fun."

The other participants differed in opinion;

"Yeah, I would call that bullying ... you would feel vulnerable." (Participant 1)

The subjective factors that were identified from the research which came from the participants can be summarised visually in the diagram below.

Positive self-concept and self-awareness (Participant 4)

A bit of a laugh and a bit of fun (Participant 1)

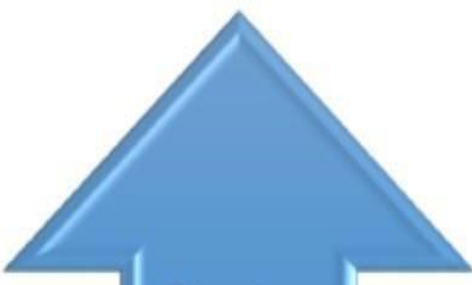

Dignity

and

Respect

Respect everyone's rights (Participant 3)

Reducing stigma (Participant 2)

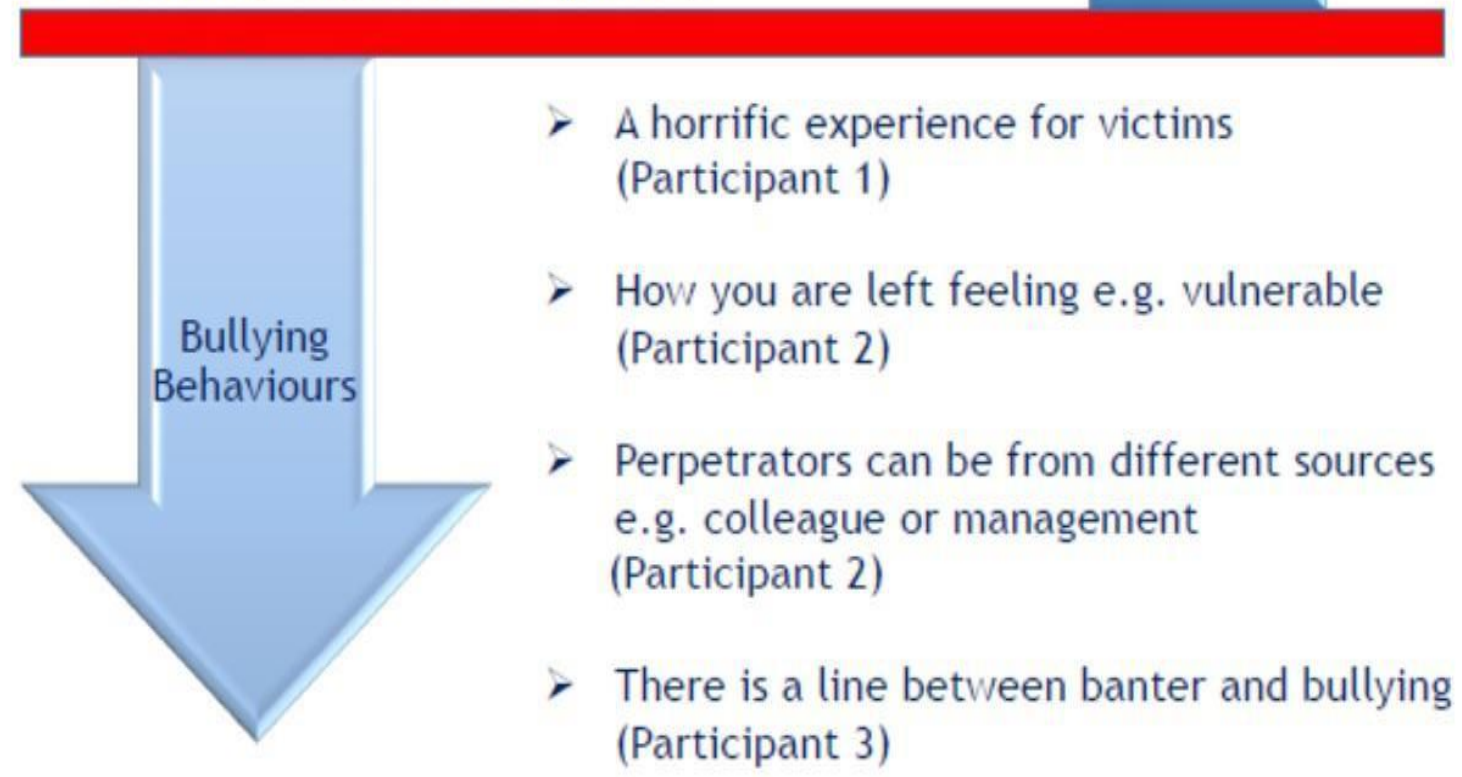

Figure 3. Crossing the line from a culture of dignity and respect to bullying behaviours 


\section{Some suggestions for preventing workplace bullying}

Direct quotes from respondents

1. Transparency. No negative consequences for speaking up.

Support from management. A culture in the workplace where bullying is not tolerated

2. Clear policy. Positive staff relations

3. Management training

4. A good spirit fostered from management down

5. Open communication, information

6. Educate people about where they can report as often it's a person in authority who is the bully so people need to know where they can go to report it.

7. Awareness in the workplace of the problem. Making sure everyone is included. Have guidelines in place that everyone is aware of re cyber bullying etc.

8. Very clear guidelines and policies in place regarding processing a complaint

\section{Summary of most important findings and contribution of findings}

- The variance in opinions which was apparent both from the responses to the scenarios posited in the questionnaires and within the focus group when discussing a single scenario is an important finding. This shows that subjective views are different when perceiving certain situations and attributing negative behaviours to be bullying. This variance needs to be considered by practitioners and mediators when dealing with workplace bullying and awareness should be raised about this discrepancy.

- Resilience levels were also a recurring theme in the focus group whereby the possibility of resilience training should be considered by managers. At the very least, awareness should be raised regarding the wide sensitivity and resilience continuum which exists between different individuals and how this may affect their experience of negative behaviours or 'banter' in the workplace.

- Self-identification and identification of bullying victims and bullies is another issue which was found to be of concern to employees. Therefore, more focus should be placed on this in the future to reduce 
ambiguity when it comes to labelling perpetrators and victims.

- The most significant finding was the majority consensus that when bullying complaints are being reviewed, individuals' sensitivity levels, personal traits and subjective views on bullying should be taken into account, thereby creating cause for practitioners to consider a change in how they conduct workplace bullying mediations. This also marks a significant opportunity for further research to be conducted as to how to account for, describe and quantify individual subjectivity.

\section{Recommendations for practice}

This research, and further research in this area, could support the changes that need to be made so as to create a healthier work environment and help policy makers as they endeavour to enhance antibullying policies in Ireland. Some of the implications for future practice are listed below;

\section{Importance of definition}

Further clarification is required as to when offending behaviours cross the line from harmless banter to inappropriate behaviour in the workplace. Given the ambiguity and current definitional issues (for both bullying and banter) as discussed previously, organisations would be wise to decide upon a workplace bullying definition and make it clear to employees that this definition is what will be applied and considered when dealing with workplace bullying complaints. The definition should be given to employees at induction stage and outlined clearly within an anti-bullying policy tailored to the organisation. If any changes were to be made to the definition, employees should be made aware of this. Ideally, a universally accepted definition for workplace bullying would be generated and dispersed, but as this is unlikely in the near future, practitioners should endeavour to have a clear organisational definition for employees to refer to and the subjectivity of bullying should be referred to in policies.

Awareness of personal subjectivity and workplace bullying complaints Management and mediators should recognise and appreciate the fact that each employee is an individual and thus has individual perspectives as to what they consider bullying behaviours to be, has varying levels of sensitivity, and may be more prone to engaging in 'banter' behaviour which others could interpret as bullying.

While there must be an overarching definition for employees to be aware of, management and mediators must concern themselves with and have the wherewithal to accept that there will be subjectivity involved. Complaints should be dealt with by management and mediators in accordance to the recognition of this fact and include this recognition in their policies.

\section{Resilience training}

Building and creating an awareness within school staff culture of what constitutes behaviour by colleagues and what might undermine dignity and respect may take time. In addition to promoting this culture, organisations should consider introducing resilience training. Training in this area would be beneficial in terms of creating an environment where employees are aware that their work colleagues have different levels of sensitivity and resilience and become more self-aware of where they themselves sit on 
the spectrum. It may also help boost resilience levels which, in turn could, ensure employees feel confident in the workplace.

\section{Legislation}

Given the significant detrimental effects which have been found to occur as a result of workplace bullying, organisations should be advocating for more stringent legislative policies with regard to workplace bullying. There is currently no legal obligation for employers to have an anti-bullying policy; it is strongly advisable but not obligatory. There needs to be a more serious emphasis placed on the legal consequences and a strong argument can be made for the criminalisation of workplace bullying so as to create healthier workplace environments.

\section{Summary and conclusion}

Overall, the findings of this present study offers a contribution to the literature discussing whether or not 'bullying is in the eye of the beholder'. Primarily, the study's findings show that there are very significant subjective discrepancies in individuals' viewpoints as to what constitutes bullying in the workplace and participants have been shown to have varying opinions ranging from 'strongly disagree' to 'strongly agree' regarding whether particular situations constitute workplace bullying.

These findings are significant when it comes to management passing judgment on workplace bullying complaints because subjective factors such asself- identification, subjective views and resilience levels should be considered as these will affect what cases are referred to mediation. These issues will all play a part in determining the outcome of a bullying complaint but are currently not being considered with enough weight, if at all. It could be argued that they should be in the future. 


\section{References}

Ayoko, O., Callan, V. J., \& Härtel, C. (2003). Workplace conflict, bullying, and counter-productive behaviors. The International Journal of Organizational Analysis, 11(4), 283-301.

Baumeister, R., Stillwell, A., \& Wotman, S. (1990). Victim and perpetrator accounts of interpersonal conflict: autobiographical narratives about anger. Journal of personality and social psychology, 59(5), 994.

Bentley, T., Catley, B., Cooper-Thomas, H., Gardner, D., O’Driscoll, M. P., Dale, A., \& Trenberth, L. (2012). Perceptions of workplace bullying in the New Zealand travel industry: Prevalence and management strategies. Tourism Management, 33(2), 351-360.

Beswick, J., Gore, J., \& Palferman, D. (2006). Bullying at work: a review of the literature (WPS/06/04). Derbyshire: Health and Safety Laboratories.

Brodsky, C. (1976). The harassed worker. DC Heath \& Co.

Connor, K., \& Davidson, J. (2003). Development of a new resilience scale: The Connor-Davidson resilience scale (CD-RISC). Depression and anxiety, 18(2), 76-82.

Di Rosa, A., Gangemi, S., Cristani, M., Fenga, C., Saitta, S., Abenavoli, E., Imbesi, S., Speciale, A., Minciullo, P., Spatari, G., Abbate, S., Saija., A,

\& Cimino, F. (2009). Serum levels of carbonylated and nitrosylated proteins in mobbing victims with workplace adjustment disorders. Biological psychology,82(3), 308-311.

Einarsen, S., Raknes, B., \& Matthiesen, S. (1994). Bullying and harassment at work and their relationships to work environment quality: an exploratory study. European Work and Organisational Psychologist, 4(4), 381401.

Einarsen, S., Hoel, H., Zapf, D., \& Cooper, C. (2003). The concept of bullying at work: The European tradition. Bullying and emotional abuse in the workplace: International perspectives in research and practice. London: Taylor \& Francis.

\section{EMPLOYMENT EQUALITY ACT 1998 (CODE OF PRACTICE) (HARASSMENT) ORDER}

2012. http://www.irishstatutebook.ie/eli/2012/si/208/made/en/pdf

(accessed 23 November 2017).

Hoel, H., Rayner, C., \& Cooper, C.(1999). Workplace bullying. John Wiley \& Sons Ltd.

Ireland, C., \& Ireland, J. (2000). Descriptive analysis of the nature and extent of bullying behavior in a maximum-security prison. Aggressive Behavior,26(3), 213-223.

Jackson, D., Firtko, A., \& Edenborough, M. (2007). Personal resilience as a strategy for surviving and thriving in the face of workplace adversity: a literature review. Journal of advanced nursing, 60(1), 1-9.

Jenkins, M. (2011). Practice note: Is mediation suitable for complaints of workplace bullying?. Conflict Resolution Quarterly, 29(1), 25-38.

Keashly, L., Trott, V., \& MacLean, L. (1994). Abusive behaviour in the workplace: A preliminary investigation. Violence and victims, 9(4), 341- 357.

Kulig, J. (2000). Community resiliency: The potential for community health nursing theory development.

Public Health Nursing, 17(5), 374-385. 
Lazarus, R., \& Folkman, S. (1984). Stress. Appraisal, and coping, 725. Leech, G. (2016). Principles of pragmatics. Routledge.

Mikkelsen, E., \& Einarsen, S. (2001). Bullying in Danish work-life: Prevalence and health correlates. European journal of work and organizational psychology, 10(4), 393-413.

NASUWT. (1996). No Place to Hide: Confronting Workplace Bullies, Birmingham: NASUWT.

Niedl, K. (1995). Mobbing/bullying at the work place. Munich: Rainer Hampp.

O'Driscoll, M., Cooper-Thomas, H., Bentley, T., Catley, B., Gardner, D., \& Trenberth, L. (2011). Workplace bullying in New Zealand: A survey of employee perceptions and attitudes. Asia Pacific Journal of Human Resources, 49(4), 390-408.

Oxford English Dictionary Online (2017). https://en.oxforddictionaries.com/definition/banter (accessed 19 November 2017).

Parzefall, M., \& Salin, D. M. (2010). Perceptions of and reactions to workplace bullying: A social exchange perspective. Human Relations, 63(6), 761- 780.

Quine, L. (1999). Workplace bullying in NHS community trust: staff questionnaire survey. Bmj, 318 (7178), 228-232.

Rayner, C., \& Keashly, L. (2004). Bullying at work: A perspective from Britain and North America. Counterproductive work behavior. Washington DC: American Psychological Association.

Rutter, M. (1985). Resilience in the face of adversity. British journal of psychiatry, 147(1), 598-611.

Salin, D. (2001). Prevalence and forms of bullying among business professionals: A comparison of two different strategies for measuring bullying. Europeanjournal of work and organizationalpsychology, 10(4), 425-441. Saunders, P., Huynh, A., \& Goodman-Delahunty, J. (2007). Defining workplace bullying behaviour professional lay definitions of workplace bullying. International journal of law and psychiatry, 30(4), 340-354.

Terpstra, D., \& Baker, D. (1991). Sexual harassment at work: The psychosocial issues.

Tugade, M., \& Fredrickson, B. L. (2004). Resilient individuals use positive emotions to bounce back from negative emotional experiences. Journal of personality and social psychology, 86(2), 320.

Vartia, M. (2001). Consequences of workplace bullying with respect to the well- being of its targets and the observers of bullying. Scandinavian journal of work, environment \& health, 63-69.

Zapf, D., \& Einarsen, S. (2011). Individual antecedents of bullying: Victims and perpetrators. Bullying and harassment in the workplace: Developments in theory, research, and practice, 177-200.

Siobhan Healy Cullen has acted as HR Coordinator for Group Support Functions and also as a Group Learning in her role as a Human Resource specialist in financial institutions. She has also acted as the Engagement Coordinator, providing support for learning and engagement related projects and initiatives in this business. She is currently a PhD student at Massey University, Manawatū campus, New Zealand. 